Article

\title{
Heat Transfer in Directional Water Transport Fabrics
}

\author{
Chao Zeng, Hongxia Wang *, Hua Zhou and Tong Lin \\ Institute of Frontier Materials, Deakin University, Geelong VIC 3216, Australia; zech@deakin.edu.au (C.Z.); \\ hua.zhou@deakin.edu.au (H.Z.); tong.lin@deakin.edu.au (T.L.) \\ * Correspondence: hong.wang@deakin.edu.au; Tel.: +61-03-5227-2083 \\ Academic Editor: Jinlian Hu \\ Received: 18 May 2016; Accepted: 1 September 2016; Published: 14 October 2016
}

\begin{abstract}
Directional water transport fabrics can proactively transfer moisture from the body. They show great potential in making sportswear and summer clothing. While moisture transfer has been previously reported, heat transfer in directional water transport fabrics has been little reported in research literature. In this study, a directional water transport fabric was prepared using an electrospraying technique and its heat transfer properties under dry and wet states were evaluated, and compared with untreated control fabric and the one pre-treated with $\mathrm{NaOH}$. All the fabric samples showed similar heat transfer features in the dry state, and the equilibrium temperature in the dry state was higher than for the wet state. Wetting considerably enhanced the thermal conductivity of the fabrics. Our studies indicate that directional water transport treatment assists in moving water toward one side of the fabric, but has little effect on thermal transfer performance. This study may be useful for development of "smart" textiles for various applications.
\end{abstract}

Keywords: heat transport; directional water transport; conduction; radiation

\section{Introduction}

Considerable interest has been devoted to developing fabrics with self-driven directional water transport function over recent years [1-8]. The concept of directional fluid transport, which is also called "one-way liquid transport" or "fluid diode" is a phenomenon widely found in daily life. Examples can be found in one-dimensional (1D) materials, such as spider silk and its inspired designs for water-harvesting [9-17], two-dimensional (2D) solid surfaces which are fabricated typically by forming a chemical gradient [18-23], or chemically homogeneous but surface roughness variation [24-28] using various approaches, and three-dimensional (3D) porous materials such as textile fabrics [1,5-7,29-33], cellulosic paper substrate [34], and electrospun nanofibrous membranes [3,7]. The 3D porous materials with directional water transport property are prepared either by forming a hydrophobicity-to-hydrophilicity gradient or two zones with opposite wettability across thickness. When worn next to the skin, directional water transport fabrics allow sweat to be transferred rapidly from the body surface to the external garment, leaving a dry microenvironment, hence maintaining the wearer in a comfortable state, especially useful for making sportswear and summer clothing.

In hot weather or high intensive activities, peoples sweat a lot, and the excessive sweating often leads to discomfort wet and clinging feel and even heatstroke due to the inefficient thermal dissipation [35]. Heat transfer in porous media involves three main routes: conduction, convection, and radiation, and heat transfer via conduction is more significant than the others [36]. In addition, the evaporation of moisture from fabric also contributes to heat dissipation, especially when the fabric is wetted with water or sweat. Despite the fact that thermal transfer in conventional fabrics has widely been studied [37-40], little is reported on the thermal transfer behavior of directional water transport fabrics.

In our previous study, we developed a two-step method to prepare directional water transport polyester fabric, which involves pre-treatment of the fabric substrate with $\mathrm{NaOH}$ followed by 
electrospraying of SU-8 on one side of the fabric [33]. The treated fabric showed excellent one-way water transport ability with a one-way moisture transport index (also known as $R$ value) of 850 and -157 on the sprayed and the unsprayed sides, respectively. In this study, we examined the heat transfer feature of this SU-8 treated directional water transport fabric in both dry and wet states.

\section{Experimental}

Materials. $\mathrm{NaOH}$ was purchased from Aldrich. SU-8 2075 was provided by Microchem Corporation (Westborough, MA, USA). A commercial polyester fabric (plain weave, $168 \mathrm{~g} / \mathrm{m}^{2}$, thickness $=420 \mu \mathrm{m}$ ) was used as substrate.

Preparation of coating solution. A commercial SU-8 organic resin solution (1.4 g) was mixed with acetone $(100 \mathrm{~mL})$ in the dark to form a homogeneous solution.

Pre-treatment of fabric substrate. The polyester fabric was pre-treated with $10 \%$ aqueous $\mathrm{NaOH}$ at $60{ }^{\circ} \mathrm{C}$ for $25 \mathrm{~min}$ to allow the hydrolysis of the surface fiber layer. After pretreatment, the fabric was rinsed with water, $3 \%$ acetic acid solution and water again, and finally dried at room temperature in air for $24 \mathrm{~h}$.

Coating treatment. The SU-8 solution was electro-sprayed on one side of the $\mathrm{NaOH}$ pre-treated fabric using a purpose-made electrospraying device. During electrospraying, the solution feeding rate was controlled by a syringe pump (KD Scientific Inc., Holliston, MA, USA) at $30 \mathrm{~mL} / \mathrm{h}$. A high voltage was applied between the nozzle and the counter electrode using a DC power supply (Gamma High Voltage) (see detail process in the literature [33]). The coated fabric was irradiated by UV light $\left(80 \mathrm{~mW} / \mathrm{cm}^{2}\right)$ for $10 \mathrm{~min}$, and then heated at $95^{\circ} \mathrm{C}$ for $1 \mathrm{~min}$. For comparison, a dip-coating technique was also used to apply SU-8 onto the entire polyester fabric [41].

Characterizations: The surface morphology of fabrics was observed on a Supra 55VP scanning electron microscope (Carl Zeiss, Oberkochen, Germany) operated under the acceleration voltage of $5 \mathrm{kV}$. The heat transfer properties were measured using a purpose-designed device consisting of a Fluke 289 RMS digital thermometer (Fluke Corporation, Everett, WA, USA), a thermocouple probe, and a Julabo 5EH water circulation bath system (Julabo $\mathrm{GmbH}$, Seelbach, Germany) to control the temperature of a hot plate. During testing, the fabric sample was mounted on the hot plate and the fabric temperature change was monitored by the thermocouple and digital meter. This temperature monitoring system was calibrated against boiling water and ice-water. The surface temperature of fabrics was measured using a thermal image infrared (IR) camera (NEC thermo tracer IR camera, Japan). The camera has a sensitivity of $0.03{ }^{\circ} \mathrm{C}$ and an accuracy of $\pm 2{ }^{\circ} \mathrm{C}$ when used for recording the surface temperature change. The data recorded was processed by software (Image Pro 4.0.6, NEC Avio Infrared Technologies Co., Ltd., Tokyo, Japan). All samples for thermal transfer related tests were put into the conditioned room $\left(23 \pm 1{ }^{\circ} \mathrm{C}\right.$, relative humidity $65 \% \pm 2 \%$, refer to ASTM D1776) for at least $24 \mathrm{~h}$ prior to testing.

\section{Results and Discussion}

To prepare the directional water transport fabric, SU-8/acetone solution was deposited on one side of the $\mathrm{NaOH}$ pre-treated polyester fabric using our previously developed method [33]. The chemical structure of SU-8 is shown in Figure 1a and the apparatus for one-side electrospraying treatment is schematically illustrated in Figure $1 \mathrm{~b}$. By precisely controlling the weight loading of SU-8 on the fabric, a directional water transport fabric can be prepared. Figure 1c,d shows the SEM images of the polyester fabric after $\mathrm{NaOH}$ pre-treatment and after further SU-8 electrospraying. The $\mathrm{NaOH}$ pre-treated fabric showed a smooth fiber surface (Figure 1c). After electrospraying, a thin coating was formed on the fiber surface (Figure 1d).

Figure 2 illustrates the directional water transport feature of the sprayed fabric. In this study, the weight load of SU-8 on the fabric was controlled at $0.6 \mathrm{~g} / \mathrm{m}^{2}$. When water (colored with red dye) was dropped on the SU-8 sprayed surface, it penetrated through the fabric and spread into 
the uncoated fabric matrix (Figure 2a). However, when water was dropped on the uncoated side (Figure 2b), it just spread into the uncoated fibrous matrix layer without penetrating through the fabric.

The formation of directional water transport effect on the $\mathrm{NaOH}$ pre-treated polyester fabric was explained as the asymmetric wettability along the fabric thickness. In our previous paper [33], we showed that treatment with $\mathrm{NaOH}$ gives the polyester fiber a hydrophilic surface because of the hydrolysis of polyester in alkaline conditions. SU-8 treatment allowed the treated fibers to have a hydrophobic feature. When SU-8 was electrosprayed on one side of the $\mathrm{NaOH}$ pre-treated polyester fabric, directional water transport effect occurred depending on the SU-8 coating layer thickness on the fabric. When the thickness was at $58.5 \mu \mathrm{m}$, the treated fabric showed the best directional water transport ability.

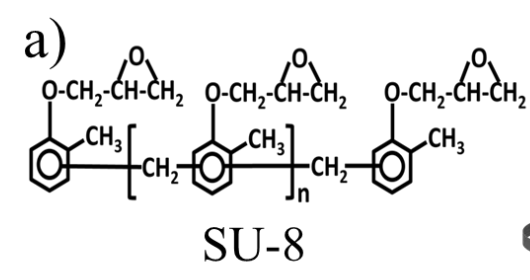

b)

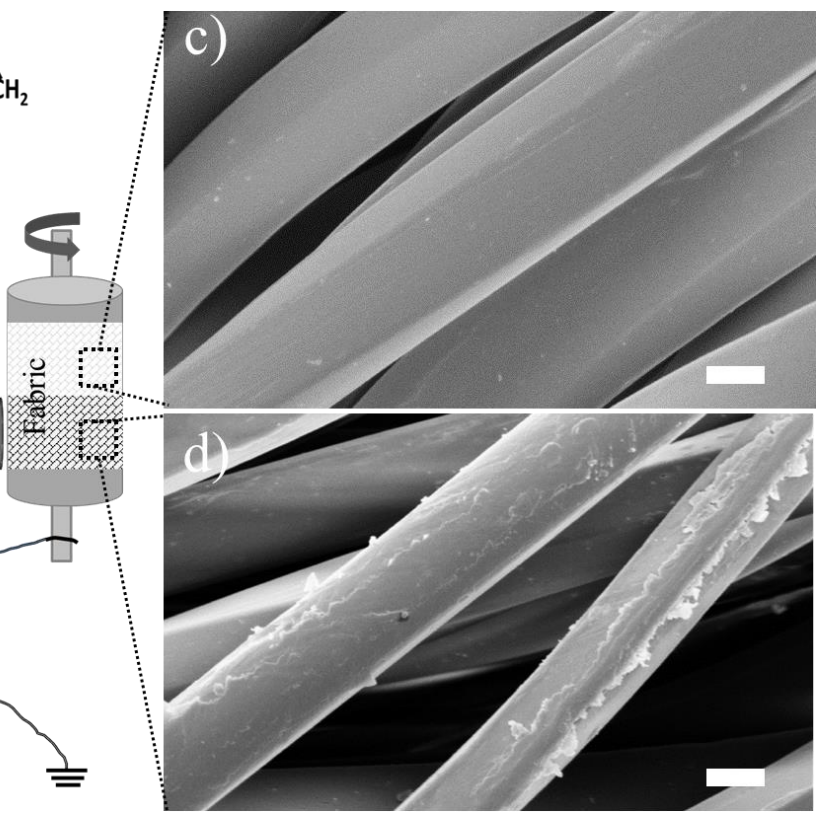

Figure 1. (a) Chemical structure of SU-8; (b) Schematic of apparatus for one-side electro-spraying treatment of fabric; (c,d) SEM images of the (c) $\mathrm{NaOH}$ pre-treated and (d) electrosprayed polyester fabric (scale bar, $10 \mu \mathrm{m}$ ).

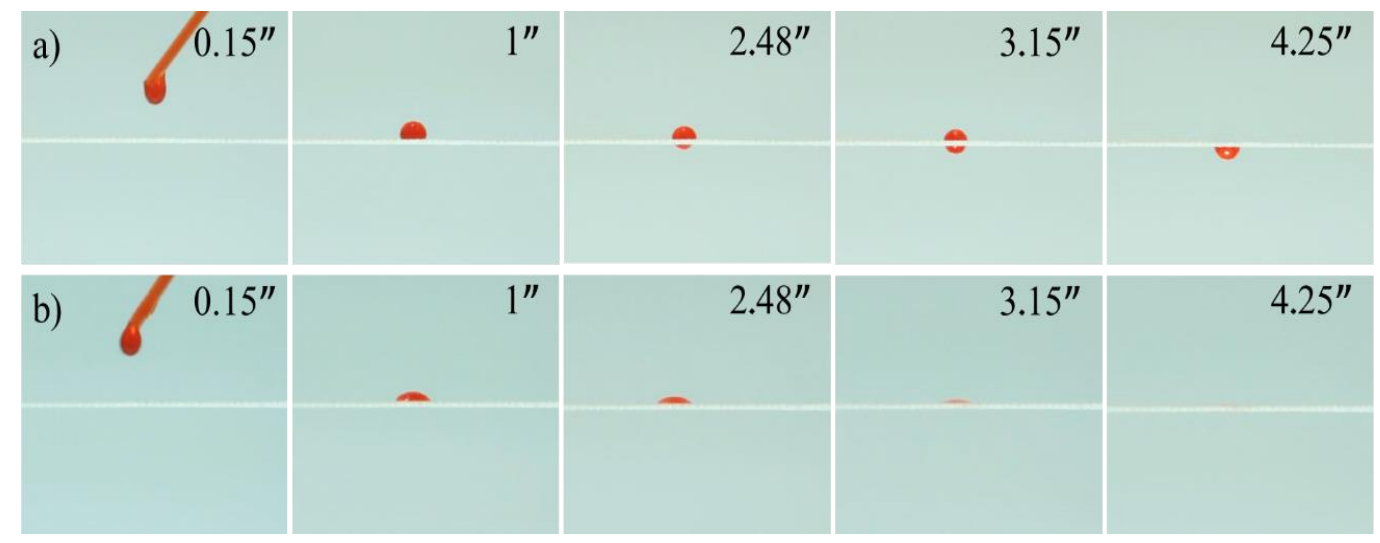

Figure 2. Still frames taken from digital videos to show dropping red-dyed water on the one-side electro-sprayed polyester fabric, (a) on the SU-8 sprayed surface; (b) on the unsprayed back surface.

Figure 3a shows the setup for measuring the temperature change on fabric when it contacts with a hot plate where the surface temperature was controlled at $37^{\circ} \mathrm{C}$. The accuracy of the thermocouple in the setup was checked by measuring (i) boiling water and (ii) ice-water at ambient pressure. As shown 
in Figure 3b, at ambient pressure, the boiling water and ice-water were measured to have temperatures of $99.67^{\circ} \mathrm{C}$ and $0.11^{\circ} \mathrm{C}$, respectively, indicating reasonable accuracy $\left(<0.33^{\circ} \mathrm{C}\right)$. However, a larger experimental error could result when measuring a thin porous fabric using a thermal couple due to the incomplete contact of the thermocouple bead with the porous fabric. Normally, ${ }^{\circ} \mathrm{C}$ of experimental error is expected for this measurement.

Figure $3 c, d$ shows the temperature change of the fabric samples upon touching the hot plate. The fabric temperature increased initially and then reached an equilibrium value. In the dry state, the $\mathrm{NaOH}$ pre-treated fabric and the directional water transport fabric had similar equilibrium temperatures, $\left(36.1{ }^{\circ} \mathrm{C}\right.$ and $36.2{ }^{\circ} \mathrm{C}$, respectively). For comparison, we also coated the entire fabric with SU-8 using a dip-coating technique and measured the temperature change on the hot plate, which was similar (equilibrium temperature of $36.2^{\circ} \mathrm{C}$ ). In addition, the control fabric without $\mathrm{NaOH}$ treatment was evaluated under the same conditions, which showed a similar temperature profile and equilibrium temperature to the other fabric samples.
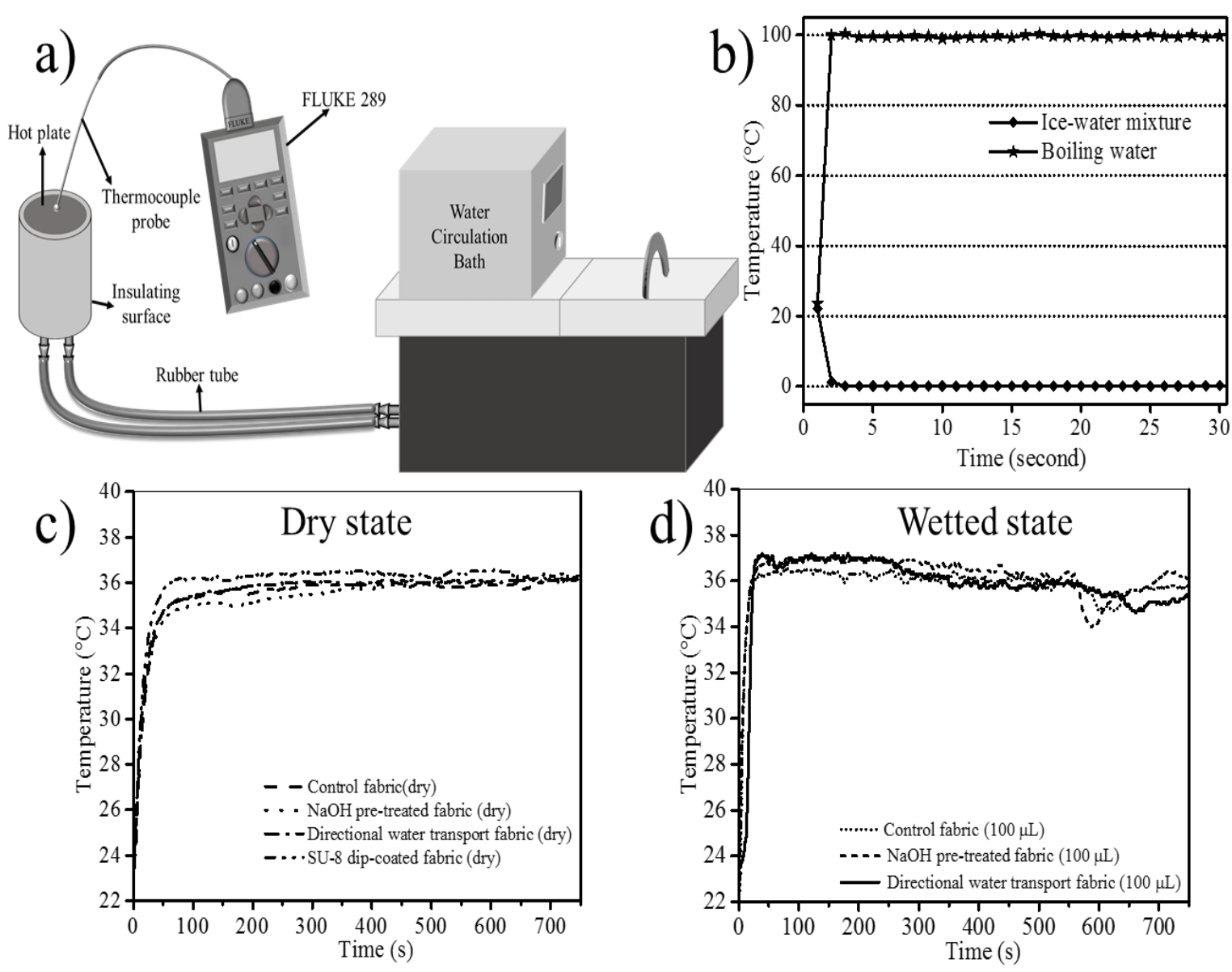

Figure 3. (a) Schematic of the purpose-built setup for measuring the heat transfer property of fabrics; (b) temperature of boiling water and ice-water mixture measured by thermocouple; and $(\mathbf{c}, \mathbf{d})$ temperature-time curves of the $\mathrm{NaOH}$ pre-treated fabric, directional water transport fabric and SU-8 dip-coated fabric in dry (c) and wetted (d) states.

When the fabrics were brought into contact with the hot plate and then pre-wetted with water, they showed different equilibrium temperature to the dry state. A large difference was observed in the control, the pre-treated and the directional water transport fabric due to their different wettability to water. When $100 \mu \mathrm{L}$ water was dropped on the control fabric, it took more than $10 \mathrm{~s}$ to spread into the matrix. However, when the same amount of water was dropped onto the $\mathrm{NaOH}$ treated fabric, water spread into the fabric in 1-2 s. This is because $\mathrm{NaOH}$ treatment gives the polyester fabric a hydrophilic 
surface. Water can also move rapidly into the directional water transport fabric when it was dropped on the sprayed side because of the one way transport effect, however it just spread in the hydrophilic layer. The four fabric samples showed similar equilibrium temperatures, suggesting that they were eventually heated up to a similar temperature level.

The major difference in temperature between the fabric samples was found in the inflection point. The time to reach the inflection point varied between the fabrics. As shown in Figure $3 \mathrm{~d}$, the control fabric, $\mathrm{NaOH}$ pre-treated fabric and directional water transport fabric took 586, 599 and $661 \mathrm{~s}$ to reach the inflection point, respectively. The different inflection point can be explained by the difference in thermal conductivity and the effect of liquid water on thermal transfer in fabric. The directional water transport fabric was wetted in the areas where were not coated with SU-8, where the SU-8 coated layer was in a dry state. However, water penetrated into the entire fabric matrix with different speed on the control fabric (more than $10 \mathrm{~s}$ ) and $\mathrm{NaOH}$ pre-treated fabric (within $1 \mathrm{~s}$ ).

For practical applications where skin is covered with directional water transport fabric, sweat penetrates the inner hydrophobic layer and wicks into the external hydrophilic layer. The non-wetting feature of the hydrophobic surface prevents the fabric from sticking to the skin surface, leaving a dry and comfortable micro-environment for the wearer. Moving sweat on the external surface assists in water evaporation. Here, the temperature-time curve for the SU-8 dip-coated fabric in the wet state was unavailable due to the hydrophobicity property of the fabric.

To understand the above results, we measured the thermal conductivity of the fabrics. As listed in Table 1, the thermal conductivity increased from $54.6 \pm 1.4$ to $61.3 \pm 1.5 \mathrm{~mW} / \mathrm{mK}$ after electro-spraying treatment on one side, $12.27 \%$ enhancement in the thermal conductivity was attained. When the fabrics were wetted with $100 \mu \mathrm{L}$ water, an increase in thermal conductivity for the $\mathrm{NaOH}$ pre-treated fabric $(436.21 \pm 5.61 \mathrm{~mW} / \mathrm{mK})$ and directional water transport fabric $(316.3 \pm 3.2 \mathrm{~mW} / \mathrm{mK})$ resulted Therefore, increased maximum temperature comes from the effect of SU-8 coating and wetting on the fabric's thermal conductivity.

Water contact angle (WCA) was measured to understand the wettability of the fabrics (Table 1). The WCA of the polyester fabric decreased from $118^{\circ}$ to $0^{\circ}$ after $\mathrm{NaOH}$ treatment due to the hydrolysis of polyester on the polyester fiber surface. For the directional water transport fabric, the initial contact angle on the SU- 8 coated side was $131^{\circ}$, while the uncoated side retained a WCA of $0^{\circ}$. The polyester fabric entirely coated with SU-8 showed a WCA of $131^{\circ}$ on both sides. As expected, there was no directional water transport feature on the SU-8 dip coated fabric.

Table 1. Comparison between the control fabric, $\mathrm{NaOH}$ pre-treated fabric, directional water transport fabric and SU-8 dip-coating fabrics.

\begin{tabular}{|c|c|c|c|c|}
\hline Fabric Type & Method & WCA $\left({ }^{\circ}\right)$ & Water Transport & $\begin{array}{c}\text { Thermal Conductivity } \\
(\mathrm{mW} / \mathrm{mK})\end{array}$ \\
\hline Control & - & 118 & Bidirectional & $\begin{array}{c}59.7 \pm 1.0 \text { (dry) } \\
405.4 \pm 4.2(\text { wetted })\end{array}$ \\
\hline $\mathrm{NaOH}$ treated & $\begin{array}{l}\text { Immersing in } \\
\mathrm{NaOH} \text { solution }\end{array}$ & 0 & Bidirectional & $\begin{array}{c}54.6 \pm 1.4 \text { (dry) } \\
436.2 \pm 5.6 \text { (wetted) }\end{array}$ \\
\hline $\begin{array}{l}\text { Directional water } \\
\text { transport }\end{array}$ & $\begin{array}{l}\text { SU-8 single-side } \\
\text { electrospraying }\end{array}$ & $\begin{array}{l}131 * \text { on the coated side, } \\
\text { and } 0 \text { on uncoated side }\end{array}$ & $\begin{array}{l}\text { Unidirectional (from the } \\
\text { coating to uncoated) }\end{array}$ & $\begin{array}{c}61.3 \pm 1.5 \text { (dry) } \\
316.3 \pm 3.2(\text { wetted })\end{array}$ \\
\hline SU-8 dip-coated & SU-8 dip coating & 131 on both sides & No transport & $62.5 \pm 1.0$ (dry) \\
\hline
\end{tabular}

Figure 4 shows thermal imaging results for fabric coverings on naked skin and the skin without fabric. The skin in the selected area had a uniform distribution in surface temperature (Figure 4a). Two pieces of the same fabric sample were placed on the arm, with one contacting the skin on the SU-8 coated side and the other in reverse (Figure $4 \mathrm{~b}$ ). No external force was applied on the fabrics. The image color indicates the temperature. Once the fabrics contacted the skin, they were warmed up by the skin and the surface temperature increased. The fabric surface with a temperature close to the skin surface temperature suggests a better heat transfer of the fabric. Smaller temperature difference were obtained 
with the directional water transport fabric when compared to the control fabric (Figure 4c) and the $\mathrm{NaOH}$ treated fabric (Figure $4 \mathrm{~d}$ ), indicating a better heat transfer performance.

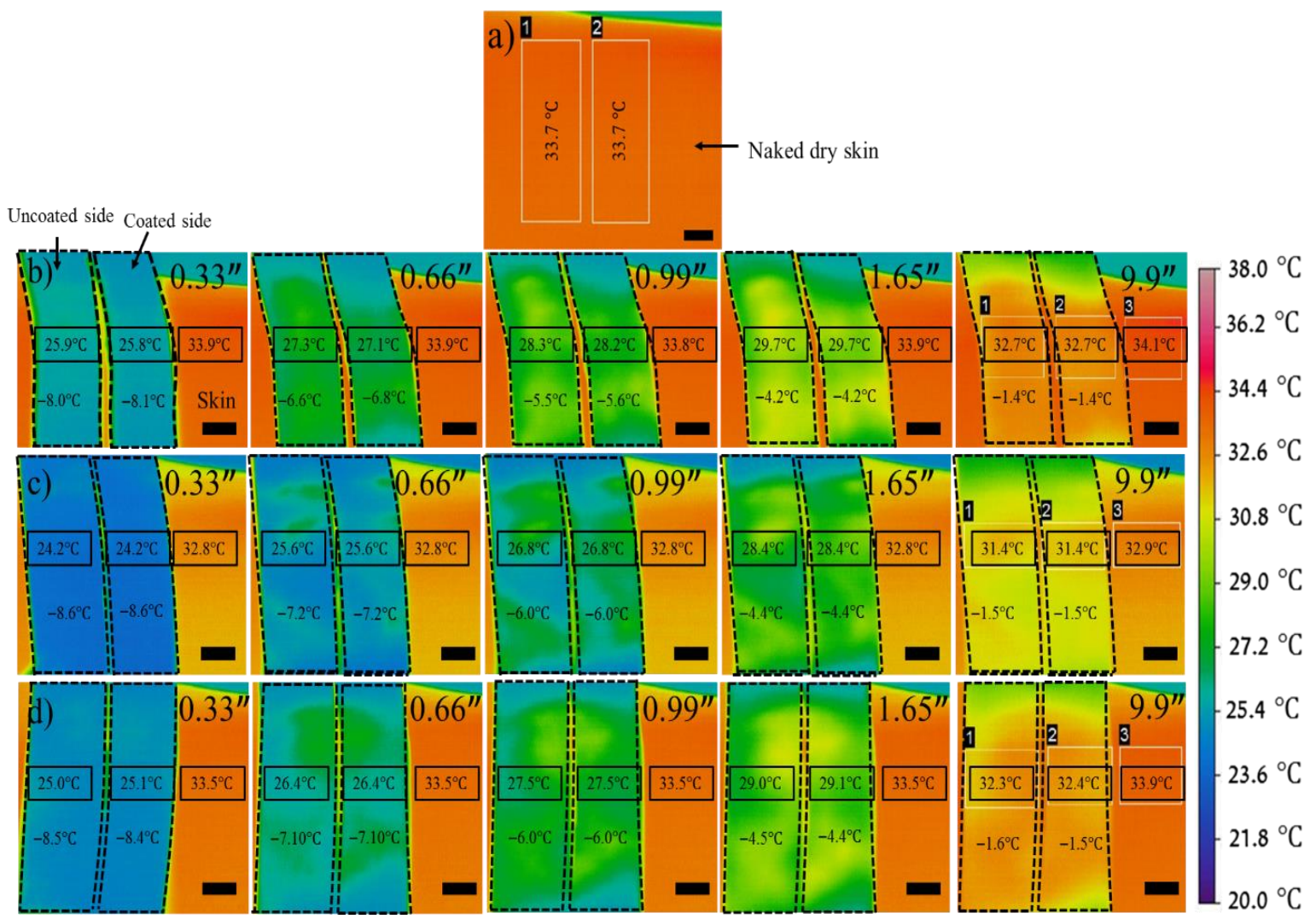

Figure 4. IR thermography images of (a) naked dry skin; naked dry skin partially covered with: (b) Directional water transport polyester fabric; (c) Control fabric; and (d) $\mathrm{NaOH}$ pre-treated fabric. The top right number indicates the time of the frame. The middle line numbers are the surface temperature on fabrics and skin. The bottom line numbers are the temperature difference between the fabrics and skin. The fabric covered areas (dashed line framed), and the other areas are naked skin (Scale bar $1 \mathrm{~cm})$.

For the directional water transport fabric, when the hydrophobic layer faces the skin, the liquid moisture generated due to perspiration can be removed rapidly from the skin surface to the external garment. This could also remove heat from the body, leaving a nice dry and cool microenvironment and hence reducing the chances to get heat stress for the wearer. Fabrics with excellent directional water transport ability and heat transfer properties are very useful for making sportswear, high performance summer clothing and special workwear.

To further prove the heat transfer property of the directional water transport fabric, we also recorded the temperature change when warm water $\left(37^{\circ} \mathrm{C}\right)$ was dropped on the directional water transport fabric (Figure 5). On the SU-8 sprayed side, the surface temperature increased rapidly and spread into a larger area (Figure 5a). The initial small spot with relatively higher temperature indicated that the water had a small contact with the fabric surface. However, when dropping water on the uncoated hydrophilic side (Figure 5b), the temperature increase spread to a larger area compared with the SU-coated surface. This asymmetric heat transfer profile on the two sides of the directional water transport fabric indicates the different heat transport profiles.

As indicated in our previous paper [41], SU-8 is hydrophobic, and water droplets on the SU-8 coated surface have a small contact area, which slows down the heat transfer to the fabric substrate. Since water rapidly penetrates through the hydrophobic layer and spreads in the hydrophilic layer, 
the temperature change mainly happens in the hydrophilic area. When water is dropped on the hydrophilic side, the temperature changes still happens in the hydrophilic matrix. This is different to dropping water on the $\mathrm{NaOH}$ treated fabric because in the latter case the temperature change takes place throughout the entire the fabric.

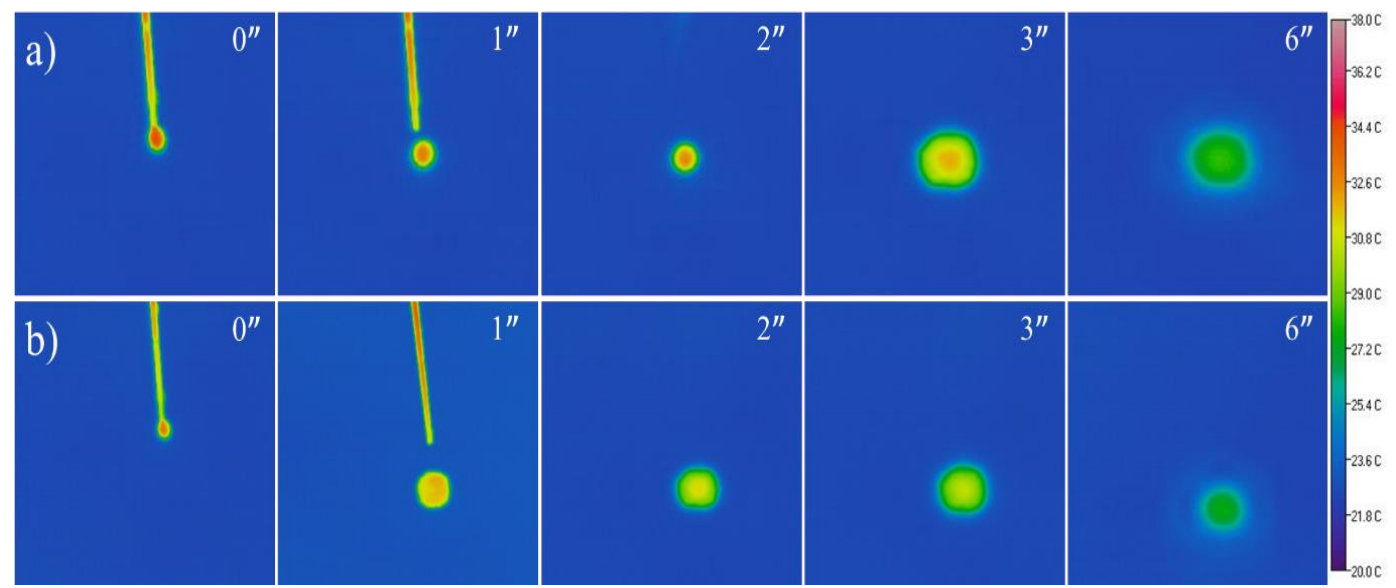

Figure 5. IR thermography images to show temperature change when dropping $37{ }^{\circ} \mathrm{C}$ water on a directional water transport fabric: (a) On the SU-8 sprayed surface; and (b) On the unsprayed back surface (Ambient temperature $23 \pm 1^{\circ} \mathrm{C}$ ).

\section{Conclusions}

Heat transfer in a SU-8 treated directional water transport fabric was studied. The untreated control fabric, $\mathrm{NaOH}$ pre-treated fabric, and directional water transport fabric showed similar heat transfer features in the dry state. All the fabric samples, including the SU-8 dip-coated one, showed higher equilibrium temperature in the dry state than the wetted state. Wetting considerably enhanced the thermal conductivity of the fabrics due to the effect of water. These results indicate that directional water transport treatment assists in moving water toward one side of the fabric, but has little effect on thermal transfer performance. This study may be useful for development of "smart" textiles for various applications such as sports garments and other active wear.

Acknowledgments: Funding support from Australian Research Council through a discovery project (DP150100406) is acknowledged.

Author Contributions: Chao Zeng performed the experiments. Hua Zhou gave technical support. Hongxia Wang and Tong Lin conceived the overall project. All authors contributed to writing the manuscript.

Conflicts of Interest: The authors declare no conflict of interest.

\section{References}

1. Wang, H.; Ding, J.; Dai, L.; Wang, X.; Lin, T. Directional water-transfer through fabrics induced by asymmetric wettability. J. Mater. Chem. 2010, 20, 7938-7940. [CrossRef]

2. Kong, Y.; Liu, Y.; Xin, J.H. Fabrics with self-adaptive wettability controlled by "light-and-dark". J. Mater. Chem. 2011, 21, 17978-17987. [CrossRef]

3. Wu, J.; Wang, N.; Wang, L.; Dong, H.; Zhao, Y.; Jiang, L. Unidirectional water-penetration composite fibrous film via electrospinning. Soft Matter 2012, 8, 5996-5999. [CrossRef]

4. Wang, H.; Wang, X.; Lin, T. Unidirectional water transfer effect from fabrics having a superhydrophobic-tohydrophilic gradient. J. Nanosci. Nanotechnol. 2013, 13, 839-842. [CrossRef] [PubMed]

5. Zhou, H.; Wang, H.; Niu, H.; Lin, T. Superphobicity/philicity janus fabrics with switchable, spontaneous, directional transport ability to water and oil fluids. Sci. Rep. 2013, 3, 2964. [CrossRef] [PubMed]

6. Tian, X.; Jin, H.; Sainio, J.; Ras, R.H.; Ikkala, O. Droplet and fluid gating by biomimetic janus membranes. Adv. Funct. Mater. 2014, 24, 6023-6028. [CrossRef] 
7. Wang, H.; Zhou, H.; Niu, H.; Zhang, J.; Du, Y.; Lin, T. Dual-layer superamphiphobic/superhydrophobicoleophilic nanofibrous membranes with unidirectional oil-transport ability and strengthened oil-water separation performance. Adv. Mater. Inter. 2015, 2, 1-7. [CrossRef]

8. Zhang, Y.; Barboiu, M. Dynameric asymmetric membranes for directional water transport. Chem. Commun. 2015, 51, 15925-15927. [CrossRef] [PubMed]

9. Lorenceau, É.; Quéré, D. Drops on a conical wire. J. Fluid Mech. 2004, 510, 29-45. [CrossRef]

10. Zheng, Y.; Bai, H.; Huang, Z.; Tian, X.; Nie, F.-Q.; Zhao, Y.; Zhai, J.; Jiang, L. Directional water collection on wetted spider silk. Nature 2010, 463, 640-643. [CrossRef] [PubMed]

11. Bai, H.; Tian, X.; Zheng, Y.; Ju, J.; Zhao, Y.; Jiang, L. Direction controlled driving of tiny water drops on bioinspired artificial spider silks. Adv. Mater. 2010, 22, 5521-5525. [CrossRef] [PubMed]

12. Bai, H.; Sun, R.; Ju, J.; Yao, X.; Zheng, Y.; Jiang, L. Large-scale fabrication of bioinspired fibers for directional water collection. Small 2011, 7, 3429-3433. [CrossRef] [PubMed]

13. Ju, J.; Bai, H.; Zheng, Y.; Zhao, T.; Fang, R.; Jiang, L. A multi-structural and multi-functional integrated fog collection system in cactus. Nat. Commun. 2012, 3, 1247. [CrossRef] [PubMed]

14. Chen, Y.; Wang, L.; Xue, Y.; Zheng, Y.; Jiang, L. Bioinspired spindle-knotted fibers with a strong water-collecting ability from a humid environment. Soft Matter 2012, 8, 11450-11454. [CrossRef]

15. Dong, H.; Wang, N.; Wang, L.; Bai, H.; Wu, J.; Zheng, Y.; Zhao, Y.; Jiang, L. Bioinspired electrospun knotted microfibers for fog harvesting. Chem. Phys. Chem. 2012, 13, 1153-1156. [CrossRef] [PubMed]

16. Hou, Y.; Gao, L.; Feng, S.; Chen, Y.; Xue, Y.; Jiang, L.; Zheng, Y. Temperature-triggered directional motion of tiny water droplets on bioinspired fibers in humidity. Chem. Commun. 2013, 49, 5253-5255. [CrossRef] [PubMed]

17. Chen, Y.; Wang, L.; Xue, Y.; Jiang, L.; Zheng, Y. Bioinspired tilt-angle fabricated structure gradient fibers: Micro-drops fast transport in a long-distance. Sci. Rep. 2013, 3, 2927. [CrossRef] [PubMed]

18. Chaudhury, M.K.; Whitesides, G.M. How to make water run uphill. Science 1992, 256, 1539-1541. [CrossRef] [PubMed]

19. Daniel, S.; Chaudhury, M.K.; Chen, J.C. Fast drop movements resulting from the phase change on a gradient surface. Science 2001, 291, 633-636. [CrossRef] [PubMed]

20. Choi, S.-H.; Zhang Newby, B.-M. Micrometer-scaled gradient surfaces generated using contact printing of octadecyltrichlorosilane. Langmuir 2003, 19, 7427-7435. [CrossRef]

21. Kraus, T.; Stutz, R.; Balmer, T.E.; Schmid, H.; Malaquin, L.; Spencer, N.D.; Wolf, H. Printing chemical gradients. Langmuir 2005, 21, 7796-7804. [CrossRef] [PubMed]

22. Yu, X.; Wang, Z.; Jiang, Y.; Zhang, X. Surface gradient material: From superhydrophobicity to superhydrophilicity. Langmuir 2006, 22, 4483-4486. [CrossRef] [PubMed]

23. Blondiaux, N.; Zürcher, S.; Liley, M.; Spencer, N.D. Fabrication of multiscale surface-chemical gradients by means of photocatalytic lithography. Langmuir 2007, 23, 3489-3494. [CrossRef] [PubMed]

24. Zhu, L.; Feng, Y.; Ye, X.; Zhou, Z. Tuning wettability and getting superhydrophobic surface by controlling surface roughness with well-designed microstructures. Sens. Actuators A 2006, 130, 595-600. [CrossRef]

25. Sun, C.; Zhao, X.-W.; Han, Y.-H.; Gu, Z.-Z. Control of water droplet motion by alteration of roughness gradient on silicon wafer by laser surface treatment. Thin Solid Films 2008, 516, 4059-4063. [CrossRef]

26. Duncombe, T.A.; Erdem, E.Y.; Shastry, A.; Baskaran, R.; Böhringer, K.F. Controlling liquid drops with texture ratchets. Adv. Mater. 2012, 24, 1545-1550. [CrossRef] [PubMed]

27. Sommers, A.; Brest, T.; Eid, K. Topography-based surface tension gradients to facilitate water droplet movement on laser-etched copper substrates. Langmuir 2013, 29, 12043-12050. [CrossRef] [PubMed]

28. Liu, C.; Ju, J.; Zheng, Y.; Jiang, L. Asymmetric ratchet effect for directional transport of fog drops on static and dynamic butterfly wings. ACS Nano 2014, 8, 1321-1329. [CrossRef] [PubMed]

29. Dong, Y.; Kong, J.; Phua, S.L.; Zhao, C.; Thomas, N.L.; Lu, X. Tailoring surface hydrophilicity of porous electrospun nanofibers to enhance capillary and push-pull effects for moisture wicking. ACS. Appl. Mater. Interfaces 2014, 6, 14087-14095. [CrossRef] [PubMed]

30. Wang, H.; Zhou, H.; Yang, W.; Zhao, Y.; Fang, J.; Lin, T. Selective, Spontaneous One-Way Oil-Transport Fabrics and Their Novel Use for Gauging Liquid Surface Tension. ACS. Appl. Mater. Interfaces 2015, 7, 22874-22880. [CrossRef] [PubMed]

31. Guo, T.; Han, K.; Heng, L.; Cao, M.; Jiang, L. Ordered porous structure hybrid films generated by breath figures for directional water penetration. RSC Adv. 2015, 5, 88471-88476. [CrossRef] 
32. Cao, M.; Xiao, J.; Yu, C.; Li, K.; Jiang, L. Hydrophobic/hydrophilic cooperative Janus system for enhancement of fog collection. Small 2015, 11, 4379-4384. [CrossRef] [PubMed]

33. Zeng, C.; Wang, H.; Zhou, H.; Lin, T. Directional Water Transport Fabrics with Durable Ultra-High One-Way Transport Capacity. Adv. Mater. Interfaces 2016, 3, 1600036. [CrossRef]

34. Mates, J.E.; Schutzius, T.M.; Qin, J.; Waldroup, D.E.; Megaridis, C.M. The fluid diode: Tunable unidirectional flow through porous substrates. ACS. Appl. Mater. Interfaces 2014, 6, 12837-12843. [CrossRef] [PubMed]

35. Wu, H.; Fan, J. Study of heat and moisture transfer within multi-layer clothing assemblies consisting of different types of battings. Int. J. Therm. Sci. 2008, 47, 641-647. [CrossRef]

36. Stanković, S.B.; Popović, D.; Poparić, G.B. Thermal properties of textile fabrics made of natural and regenerated cellulose fibers. Polym. Test. 2008, 27, 41-48. [CrossRef]

37. Chen, Y.; Fan, J.; Zhang, W. Clothing thermal insulation during sweating. Text. Res. J. 2003, 73, $152-157$. [CrossRef]

38. Majumdar, A.; Mukhopadhyay, S.; Yadav, R. Thermal properties of knitted fabrics made from cotton and regenerated bamboo cellulosic fibres. Int. J. Therm. Sci. 2010, 49, 2042-2048. [CrossRef]

39. Sampath, M.; Aruputharaj, A.; Senthilkumar, M.; Nalankilli, G. Analysis of thermal comfort characteristics of moisture management finished knitted fabrics made from different yarns. J. Ind. Text. 2012, 42, 19-33. [CrossRef]

40. Abbas, A.; Zhao, Y.; Zhou, J.; Wang, X.; Lin, T. Improving thermal conductivity of cotton fabrics using composite coatings containing graphene, multiwall carbon nanotube or boron nitride fine particles. Fibers Polym. 2013, 14, 1641-1649. [CrossRef]

41. Zeng, C.; Wang, H.; Zhou, H.; Lin, T. Self-cleaning, superhydrophobic cotton fabrics with excellent washing durability, solvent resistance and chemical stability prepared from an SU-8 derived surface coating. RSC Adv. 2015, 5, 61044-61050. [CrossRef]

(C) 2016 by the authors; licensee MDPI, Basel, Switzerland. This article is an open access article distributed under the terms and conditions of the Creative Commons Attribution (CC-BY) license (http://creativecommons.org/licenses/by/4.0/). 